\title{
Essential and Toxic Metals in Oral Fluid-a Potential Role in the Diagnosis of Periodontal Diseases
}

\author{
Malgorzata Herman $^{1}$ • Magdalena Golasik ${ }^{1}$ - Wojciech Piekoszewski ${ }^{1,2}$. \\ Stanislaw Walas ${ }^{1}$ - Marta Napierala ${ }^{3}$ - Marzena Wyganowska-Swiatkowska ${ }^{4}$. \\ Anna Kurhanska-Flisykowska ${ }^{4}$ - Anna Wozniak ${ }^{3}$ • Ewa Florek $^{3}$
}

Received: 5 January 2016 / Accepted: 19 February 2016 / Published online: 4 March 2016

(C) The Author(s) 2016. This article is published with open access at Springerlink.com

\begin{abstract}
Recently, many studies have investigated the relationship between the level of metals in the body and various diseases. The objective of this study was to examine any possible influence of periodontal disease upon the concentration of metals in oral fluid and blood and to explore the usability of applying cluster analysis coupled with the analysis of selected elements in oral fluid, calcium $(\mathrm{Ca})$, copper $(\mathrm{Cu})$, iron $(\mathrm{Fe})$, magnesium $(\mathrm{Mg})$, manganese $(\mathrm{Mn})$, zinc $(\mathrm{Zn})$, cadmium $(\mathrm{Cd})$ and lead $(\mathrm{Pb})$, for effectively distinguishing people affected by periodontitis from healthy individuals. The quantification of eight metals in oral fluid and blood samples was performed by two inductively coupled plasma techniquesinductively coupled plasma mass spectrometry (ICP-MS) and inductively coupled plasma optical emission spectrometry (ICP-OES). Most of the examined elements were detected at elevated concentration in the oral fluid of periodontal patients. However, the differences were statistically significant in the case of three metals: $\mathrm{Cu}, \mathrm{Mg}$ and $\mathrm{Mn}(p<0.05)$. Approximately, fivefold increase in the concentration of $\mathrm{Cu}$, threefold-elevated
\end{abstract}

Ewa Florek

eflorek@ump.edu.pl

1 Department of Analytical Chemistry, Faculty of Chemistry, Jagiellonian University, 3 Ingardena Street, 30-060 Krakow, Poland

2 Laboratory of High Resolution Mass Spectrometry, Regional Laboratory of Physicochemical Analysis and Structural Research, Faculty of Chemistry, Jagiellonian University, 3 Ingardena Street, 30-060 Krakow, Poland

3 Laboratory of Environmental Research, Department of Toxicology, Faculty of Pharmacy, Poznan University of Medical Sciences, 30 Dojazd Street, 60-631 Poznan, Poland

4 Department of Conservative Dentistry and Periodontology, Poznan University of Medical Sciences, 60-820 Poznan, Poland levels of $\mathrm{Mn}$ and a twofold increase in the concentration of $\mathrm{Mg}$ were found in the oral fluid of the periodontal patients compared to the controls. Cluster analysis confirmed the statistical significance of the differences in the level of metals in the oral fluid between the two groups in most cases, plus enabled the correct classification of the subjects into patients and controls. The relationship between concentrations of metals and periodontal disease may in the future serve to prevent the development of such disease.

Keywords Oral fluid $\cdot$ Metals $\cdot$ ICP $\cdot$ Periodontal disease

\section{Introduction}

Measurements of the concentration of various substances in the blood and urine form the basis of diagnostic tests and various scientific investigations. In recent years, researchers have been looking for other biological materials which have as much informative value as blood, but are cheaper and less troublesome in their collection. Examples of these types of materials are nails, hair [1] and oral fluid (saliva) [2]. However, before it can be used to assess the state of human health, it is necessary to verify that the concentration of the test specimen in the oral fluid is correlated with its concentration in blood.

The determination of metals in biological fluids causes many problems. First of all, this type of material is characterized by a complex matrix, which may lead to numerous interferences during analysis. Moreover, many metals are present in biological materials at such low concentrations that highly sensitive analytical methods are required for their quantification [3].

Elemental analysis of biological samples mainly involves spectroscopic methods among which most commonly used 
are inductively coupled plasma optical emission spectroscopy (ICP-OES) and inductively coupled plasma mass spectrometry (ICP-MS). These techniques permit the carrying out of the simultaneous determination of numerous elements, and they also have good metrological parameters, such as low detection limits $[3,4]$.

Mineral deficiencies cause specific human body dysfunctions [5]. At the same time, the accumulation of toxic or essential metals may also lead to serious health problems or even to death $[6,7]$. Recently, many studies have investigated the relationship between the level of metals in the body and various diseases, as well as the mutual interactions between elements [8-12]. Most of the relevant publications are concerned with the relationship between the content of microelements in the body and the incidence of cancer [8, 11-13]. Other diseases, such as cardiovascular disease [9] and hepatitis C [10] have also been considered in this context.

Periodontal diseases are mainly chronic inflammatory conditions of the tissues surrounding, supporting and protecting the teeth. Severe periodontitis can lead to the loosening and loss of teeth [14]. The weakening of the body's defence mechanisms, thereby increasing the susceptibility to bacterial infection of the periodontal tissues, is dependent on many factors. These can be divided into two group: determinants over which man has no control and the risk factors that increase susceptibility to periodontal disease. Factors such as genetics, sex, race, age, and socioeconomic status belong to the first group, while the second one includes smoking, poor oral hygiene, hormones, improper diet, taking certain drugs, stress and numerous diseases, such as diabetes, osteoporosis and AIDS. Periodontal disease is widespread among the human population and is considered a social disease $[15,16]$.

Due to high prevalence of periodontal diseases, the identification of biomarkers that can help in clinical evaluation of periodontal status is important. Therefore, many investigators have tried to identify markers specific to periodontitis. Traditionally, diagnosis was based on the measurement of specific biochemical parameters in blood or gingival crevicular fluid, but lately saliva has become a biological material of choice [17]. Among many recognized salivary biomarkers are cytokines, matrix metalloproteinases (MMP)-8 and (MMP)-9 and microbial periodontal pathogens (e.g. Prevotella intermedia, Porphyromonas gingivalis) [17-19]. Saliva also allows to identify stages of periodontal disease [18]. Considering many biological functions of metals, the examination of the elemental profile during periodontal disease and the identification of changes in the level of metals seem to be interesting and have potential diagnostic value.

The objective of this investigation was to study the usefulness of available methodology to determine the concentration of selected metals in the oral fluid and blood of patients with periodontitis and then compare them with those of healthy controls, by two techniques: ICP-MS and ICP-OES. The possible influence of periodontal disease upon the concentration of metals, calcium $(\mathrm{Ca})$, copper $(\mathrm{Cu})$, iron $(\mathrm{Fe})$, magnesium $(\mathrm{Mg})$, manganese $(\mathrm{Mn})$, zinc $(\mathrm{Zn})$, cadmium $(\mathrm{Cd})$ and lead $(\mathrm{Pb})$, in oral fluid and blood was examined. An attempt was also made to see if chemometric methods could distinguish people with periodontitis from healthy ones on the basis of the elemental levels in two biological materials.

\section{Materials and Methods}

\section{Subjects}

A total of 31 non-smoking patients (17 females, 14 males) diagnosed with periodontal disease were included in the present study. The patients' mean age was $34.5 \pm 10.4$ years. Diagnosis of each case was carried out by medical experts, according to clinical symptoms and the Community Periodontal Index of Treatment Needs (CPITN). Subjects were selected from patients of the Department of Conservative Dentistry and Periodontology, Poznan University of Medical Sciences, Poland. The exclusion criteria included the following: clinically significant and diagnosed illness, alcohol and drug abuse and pregnancy. The gender- and age-matched control group consisted of 29 non-smoking volunteers (19 females and 10 males, with a mean age of $31.8 \pm 16.8$ years) with healthy periodontal tissues (confirmed by dentists) and no known illnesses. All of them live in Poznan or cities of above 100,000 citizens. None of the subjects or controls was occupationally exposed to metals, and dietary supplements were not used by them. They had a typical Polish diet, mainly characterized by a high consumption of meat (pork, chicken) and dairy products, and a low consumption of whole grain products, seafood, fresh vegetables and fruits. Informed written consent was obtained from each participant prior to commencement of the study. Each subject agreed to fill in a questionnaire recording age, gender and smoking habits.

All procedures performed in the study were in accordance with the ethical standards of the institutional and national research committee and with the World Medical Association Declaration of Helsinki (version 2002). Ethical approval (Protocol Number nr 670/08) for the study was obtained from the Bioethics Committee of the Poznan University of Medical Sciences, Poland.

\section{Sample Collection}

The oral cavity was rinsed with deionized water immediately before the oral fluid collection. About $3 \mathrm{~mL}$ of unstimulated oral fluid was collected early in the morning, directly into special vessels (Salivettes). Samples of oral fluid were centrifuged at $4000 \mathrm{rpm}(10 \mathrm{~min})$. The blood samples (about $8 \mathrm{~mL}$ ) were withdrawn from a forearm vein, using a stainless-steel 
needle surrounded by an inert plastic cannula, and transferred to plastic tubes without anticoagulant. Before digestion, all samples were stored at $-80{ }^{\circ} \mathrm{C}$.

\section{Instrumentation and Reagents}

A microwave digestion system (Multiwave 3000, Anton Paar, Austria) equipped with eight high-pressure vessels was employed for the decomposition of samples. The Optima 2100 DV (Perkin-Elmer, USA) Inductively Coupled Plasma Optical Emission Spectrometer (ICP-OES), equipped with axially viewed plasma, was used in the determination of $\mathrm{Ca}$ and $\mathrm{Mg}$ at a wavelengths of $\lambda_{\mathrm{Ca}}=317.933 \mathrm{~nm}$ and $\lambda_{\mathrm{Mg}}=422.673 \mathrm{~nm}$. All other measurements were carried out using the Elan DRC-e (Perkin-Elmer, USA) Inductively Coupled Plasma Mass Spectrometer (ICP-MS). Mn, Fe, Cu, Zn, Cd and Pb were measured using masses of 55, 57, 65, 66, 111 and 208, respectively. The ICP methods were optimized and validated before analysis of the clinical samples. The applied analytical methods enabled the determination of each selected element with satisfactory accuracy (the relative systematic error had a value between $0.1 \%$ for Fe and $8.89 \%$ for $\mathrm{Mn}$ ), good precision (expressed by coefficient of variation in terms of repeatability was in range from $0.34 \%$ for $\mathrm{Ca}$ to $2.74 \%$ for $\mathrm{Mn}$ ) and low limits of detection (values ranged from $0.007 \mu \mathrm{g} \mathrm{L}^{-1}$ for $\mathrm{Pb}$ to $0.21 \mu \mathrm{g} \mathrm{L}^{-1}$ for $\mathrm{Fe}$ ). The measured concentrations of metals of the reference material were in good agreement with the certified values. Detailed protocols of the measurement procedures were described previously [20]. Argon (Linde, Poland), with a purity of $99.999 \%$, was used for plasma generation, nebulization and as auxiliary gas.

All reagents used in this study were of analytical-reagent grade or the highest purity available. Ultrapure deionized water (20 M $\Omega$ ), obtained from WG-HLP deionizing system (Wigo, Poland), was used throughout. Multi-element ICPMS Calibration Std 3 (containing $10 \mu \mathrm{g} \mathrm{mL}^{-1}$ of each analyte in $5 \% \mathrm{HNO}_{3}$, Perkin-Elmer Pure Plus, USA) and Multielement Standard Solution VI (containing $1000 \mathrm{mg} \mathrm{L}^{-1}$ of each analyte, Merck, Darmstadt, Germany) were used for the calibration and control of all the analytical processes. The daily test was performed with the use of Smart Tune Solution Std ELAN \& DRC-e (Perkin-Elmer, USA). Certified reference material for blood (Seronorm Trace Elements in Whole Blood, L-2; SERO AS, Billingstad, Norway) was used for the accuracy evaluation. Certified reference material for oral fluid was not commercially available.

\section{Preparation of Samples}

The acid digestion procedure was carried out using a microwave digestion system. Temperature and pressure were controlled during a heating programme with the maximum pressure and temperature of 60 bar and $242{ }^{\circ} \mathrm{C}$, respectively. The blood and oral fluid samples $(0.5 \mathrm{~mL})$ from each subject, four replicate samples of certified reference material and a blank sample were directly introduced into digestion vessels and $6 \mathrm{~mL}$ of concentrated $\mathrm{HNO}_{3}$ was added. The digested samples were transferred into $10-\mathrm{mL}$ volumetric flasks and diluted with deionized water. The sample solutions were stored in plastic vials at $4^{\circ} \mathrm{C}$.

\section{Statistical Analysis}

The normality of the dataset was verified by the KolmogorovSmirnov (with Lilliefors correction) and the Shapiro-Wilk tests $(p<0.05)$. In the next step, a basic data analysis was performed to obtain the mean values, median, range and standard deviation. Outlying results were identified by Grubb's test and omitted in further calculations.

Differences in the concentration of the various metals in oral fluid and blood between the different groups (patients vs. healthy volunteers and men vs. women) were evaluated using a two-sided Mann-Whitney test with a 0.05 significance level. Prior to that, the equality of variance was tested using the Snedecor $F$ test $(P=95 \%)$. In order to analyse, confirm and visualize the relationship among metals, a Pearson's (control group) or Spearman's (patients) correlation analysis was applied to the dataset as well as a principal component analysis (PCA), which allows reduction of the number of observed variables, without much loss of information. The data were normalized before analysis.

The last step was to classify oral fluid samples based on their trace elements concentration by using hierarchical cluster analysis (HCA). Ward's hierarchical method of agglomeration and the squared Euclidean distance as a measure of the distance between the observations were applied. The cases included in cluster analysis were randomly selected from the study groups. The results were reported in the form of a dendrogram.

Statistica 10 (StatSoft Inc., USA) was used for the statistical analyses of data.

\section{Results}

In this study, the concentrations of eight elements were measured in two groups: 31 patients with periodontitis and 29 healthy volunteers. The elements were divided into two groups: essential elements, $\mathrm{Ca}, \mathrm{Cu}, \mathrm{Fe}, \mathrm{Mg}, \mathrm{Mn}$ and $\mathrm{Zn}$, and toxic metals, $\mathrm{Cd}$ and $\mathrm{Pb}$.

\section{The Relationship Between Periodontal Disease and the Concentration of the Selected Metals in Oral Fluid and Blood}

The concentrations of eight studied metals in the oral fluid and blood of periodontal patients and healthy subjects along with basic statistical parameters are given in Tables 1 and 2 . 
Table 1 Basic statistical parameters for metals distribution in the oral fluid of patients and healthy volunteers

\begin{tabular}{|c|c|c|c|c|c|c|c|c|c|c|}
\hline \multirow[t]{3}{*}{ Elements } & \multicolumn{5}{|c|}{ Patients $(n=31)$} & \multicolumn{5}{|c|}{ Healthy volunteers $(n=29)$} \\
\hline & \multicolumn{3}{|l|}{ Whole group } & \multirow{2}{*}{$\begin{array}{l}\text { Men } \\
(n=14) \\
\text { Mean } \pm \text { SD }\end{array}$} & \multirow{2}{*}{$\begin{array}{l}\text { Women } \\
(n=17) \\
\text { Mean } \pm \text { SD }\end{array}$} & \multicolumn{3}{|l|}{ Whole group } & \multirow{2}{*}{$\begin{array}{l}\text { Men } \\
(n=10) \\
\text { Mean } \pm \text { SD }\end{array}$} & \multirow{2}{*}{$\begin{array}{l}\text { Women } \\
(n=19) \\
\text { Mean } \pm \mathrm{SD}\end{array}$} \\
\hline & Mean \pm SD & Range & Median & & & Mean \pm SD & Range & Median & & \\
\hline $\mathrm{Ca}\left(\mathrm{mg} \mathrm{L}^{-1}\right)$ & $39.2 \pm 19.4$ & $8.5-71.3$ & 42.8 & $47.7 \pm 25.1$ & $38.5 \pm 21.3$ & $35.0 \pm 18.4$ & $14.8-75.7$ & 29.8 & $22.2 \pm 8.3$ & $27.2 \pm 7.1$ \\
\hline $\mathrm{Cd}\left(\mu \mathrm{g} \mathrm{L}^{-1}\right)$ & $0.2 \pm 0.1$ & $<$ LOD -0.5 & 0.2 & $0.2 \pm 0.1$ & $0.2 \pm 0.2$ & $0.3 \pm 0.3$ & $0.04-1.0$ & 0.2 & $0.5 \pm 0.4$ & $0.3 \pm 0.3$ \\
\hline $\mathrm{Cu}\left(\mu \mathrm{g} \mathrm{L}^{-1}\right)$ & $45.1 \pm 5.0^{*}$ & $3.8-162.7$ & 26.8 & $41.0 \pm 44.0$ & $48.4 \pm 39.5$ & $8.2 \pm 5.2$ & $1.1-20.6$ & 8.2 & $8.1 \pm 2.9$ & $6.0 \pm 5.1$ \\
\hline $\mathrm{Fe}\left(\mathrm{mg} \mathrm{L}^{-1}\right)$ & $1.0 \pm 0.6$ & $0.4-2.7$ & 0.8 & $0.9 \pm 0.5$ & $1.1 \pm 0.8$ & $0.9 \pm 0.7$ & $0.2-3.5$ & 0.8 & $687.7 \pm 310.9$ & $767.4 \pm 547.1$ \\
\hline $\operatorname{Mg}\left(\mathrm{mg} \mathrm{L}^{-1}\right)$ & $9.9 \pm 5.4^{*}$ & $1.2-19.9$ & 9.2 & $11.5 \pm 5.3$ & $8.6 \pm 5.3$ & $5.2 \pm 2.5$ & $2.1-9.9$ & 4.5 & $6.1 \pm 3.0$ & $4.1 \pm 1.4$ \\
\hline $\operatorname{Mn}\left(\mu \mathrm{g} \mathrm{L}^{-1}\right)$ & $41.1 \pm 15.6^{*}$ & $<$ LOD-74.8 & 39.6 & $38.2 \pm 17.3$ & $29.3 \pm 24.2$ & $15.0 \pm 8.2$ & $0.5-32.3$ & 16.6 & $15.0 \pm 5.9$ & $15.6 \pm 7.5$ \\
\hline $\mathrm{Pb}\left(\mu \mathrm{g} \mathrm{L}^{-1}\right)$ & $15.8 \pm 8.2$ & $7.7-35.4$ & 13.0 & $16.2 \pm 9.3$ & $15.5 \pm 7.3$ & $12.4 \pm 7.9$ & $0.3-28.8$ & 10.5 & $7.8 \pm 2.6$ & $10.0 \pm 8.2$ \\
\hline $\mathrm{Zn}\left(\mu \mathrm{g} \mathrm{L}{ }^{-1}\right)$ & $79.1 \pm 103.2$ & $0.5-378.5$ & 40.6 & $58.3 \pm 60.8$ & $104.9 \pm 126.2$ & $75.3 \pm 74.4$ & $0.3-124.3$ & 57.3 & $67.0 \pm 58.9$ & $46.7 \pm 32.1$ \\
\hline
\end{tabular}

${ }^{*} p<0.05$ with respect to the control group

Among the essential metals in the oral fluid of the patients, $\mathrm{Ca}$ revealed the highest mean levels at $39.2 \mathrm{mg} \mathrm{L}^{-1}$, followed by $\mathrm{Mg}\left(9.9 \mathrm{mg} \mathrm{L}^{-1}\right)$ and $\mathrm{Fe}\left(1.0 \mathrm{mg} \mathrm{L}^{-1}\right)$. The other metals were present at relatively lower levels. The toxic metals had low concentrations, with the highest being that for $\mathrm{Pb}$ $\left(15.8 \mu \mathrm{g} \mathrm{L}^{-1}\right)$. It is worth noting that Mn concentration in the oral fluid of patients $\left(41.1 \mu \mathrm{g} \mathrm{L}^{-1}\right)$ was considerably higher compared to the value reported in another publication [23], where the mean concentration of this element was $2.94 \pm 2.83 \mu \mathrm{g} \mathrm{L}^{-1}$. On the other hand, a study of Al-Rawi and Talabani [24] presented similar results to ours (concentrations of Mn: $6.0 \pm 3.0 \mu \mathrm{g} \mathrm{L}^{-1}$ ). It can be concluded that the concentration of $\mathrm{Mn}$ in the saliva varies widely. This is probably related to the effects of diet, to dietary supplements or to different places of residence.

Similarly to the group of patients, in the control group, $\mathrm{Ca}$ (35.0 $\left.\mathrm{mg} \mathrm{L}^{-1}\right), \mathrm{Mg}\left(5.2 \mathrm{mg} \mathrm{L}^{-1}\right)$ and $\mathrm{Fe}\left(0.9 \mathrm{mg} \mathrm{L}^{-1}\right)$ were present at the highest levels in saliva among the essential metals, while $\mathrm{Pb}\left(12.4 \mu \mathrm{g} \mathrm{L}^{-1}\right)$ emerged as the major contributor among the toxic metals. The high standard deviations observed in the concentration of metals are probably due to the biological spread between individuals.
A two tailed Mann-Whitney test examination of the data showed that there were no significant differences between the levels of $\mathrm{Ca}, \mathrm{Cd}, \mathrm{Fe}, \mathrm{Pb}$ and $\mathrm{Zn}$ in the saliva of periodontitis patients and healthy donors. However, the patients affected by periodontal disease showed statistically significant increases in the salivary concentrations of $\mathrm{Cu}(550 \%), \mathrm{Mg}(190 \%)$ and Mn (273\%). The differences in salivary levels of these elements appeared to be related to periodontal disease.

The concentrations of the studied metals in the oral fluid were also evaluated for relative gender-based variations in both groups (Mann-Whitney test at $p<0.05$ ). The average levels of $\mathrm{Ca}, \mathrm{Cd}, \mathrm{Mg}, \mathrm{Mn}$ and $\mathrm{Pb}$ were higher in the oral fluid of male patients, while in the cases of $\mathrm{Cu}, \mathrm{Fe}$ and $\mathrm{Zn}$, the mean concentrations were found to be higher in the oral fluid of female (Table 1). In particular, the difference in $\mathrm{Mg}$ content between the two groups was quite considerable (8.6 $\pm 5.3 \mathrm{mg} \mathrm{L}^{-1}$ for women and $11.5 \pm 5.3 \mathrm{mg} \mathrm{L}^{-1}$ for men). However, no statistically significant differences were observed in the oral fluid concentrations of the metals between women and men from the patients' group. In the case of the control group, there were also no gender differences for metal concentrations (Table 1).
Table 2 Basic statistical parameters for metals distribution in the blood of patients

\begin{tabular}{llcll}
\hline Elements & \multicolumn{2}{l}{ Patients with periodontitis $(n=13)$} & & $\begin{array}{l}\text { Data for healthy people } \\
{[21,22]} \\
\end{array}$ \\
\cline { 2 - 3 } & Mean $\pm \mathrm{SD}$ & Range & Median & \\
\hline $\mathrm{Ca}\left(\mathrm{mg} \mathrm{L}^{-1}\right)$ & $87.0 \pm 52.6$ & $53.1-190.1$ & 68.0 & $67.3 \pm 14.3$ \\
$\mathrm{Cd}\left(\mu \mathrm{g} \mathrm{L}^{-1}\right)$ & $0.7 \pm 0.5$ & $0.2-1.5$ & 0.5 & $0.8 \pm 0.3$ \\
$\mathrm{Cu}\left(\mathrm{mg} \mathrm{L}^{-1}\right)$ & $0.6 \pm 0.2$ & $0.3-0.8$ & 0.6 & $1.0 \pm 0.2$ \\
$\mathrm{Fe}\left(\mathrm{mg} \mathrm{L}^{-1}\right)$ & $451.3 \pm 43.1$ & $377.8-499.4$ & 466.5 & $427.3 \pm 46.6$ \\
$\mathrm{Mg}\left(\mathrm{mg} \mathrm{L}^{-1}\right)$ & $37.1 \pm 21.8$ & $2.8-85.2$ & 31.9 & $32.0 \pm 3.0$ \\
$\mathrm{Mn}\left(\mu \mathrm{g} \mathrm{L}^{-1}\right)$ & $11.3 \pm 6.6$ & $<\mathrm{LOD}-19.3$ & 10.0 & $8.7 \pm 2.4$ \\
$\mathrm{~Pb}\left(\mu \mathrm{g} \mathrm{L}^{-1}\right)$ & $25.1 \pm 19.5$ & $6.5-46.7$ & 19.0 & $41.5 \pm 16.5$ \\
$\mathrm{Zn}\left(\mathrm{mg} \mathrm{L}^{-1}\right)$ & $2.2 \pm 0.7$ & $1.3-3.4$ & 2.0 & $5.3 \pm 1.0$ \\
\hline
\end{tabular}


Table 3 Correlation coefficient matrix of selected elements in the oral fluid of periodontal patients $(n=31)$

\begin{tabular}{|c|c|c|c|c|c|c|c|c|}
\hline & $\mathrm{Ca}$ & $\mathrm{Cd}$ & $\mathrm{Cu}$ & $\mathrm{Fe}$ & $\mathrm{Mg}$ & $\mathrm{Mn}$ & $\mathrm{Pb}$ & $\mathrm{Zn}$ \\
\hline $\mathrm{Ca}$ & 1.000 & $0.455^{*}$ & 0.134 & 0.005 & $0.540^{*}$ & -0.252 & $0.752 *$ & 0.038 \\
\hline $\mathrm{Cd}$ & & 1.000 & 0.229 & -0.073 & 0.097 & 0.041 & $0.400 *$ & -0.321 \\
\hline $\mathrm{Cu}$ & & & 1.000 & -0.124 & -0.122 & 0.050 & 0.280 & 0.236 \\
\hline $\mathrm{Fe}$ & & & & 1.000 & -0.237 & $0.499 *$ & 0.111 & 0.115 \\
\hline $\mathrm{Mg}$ & & & & & 1.000 & -0.211 & 0.159 & -0.152 \\
\hline $\mathrm{Mn}$ & & & & & & 1.000 & -0.354 & -0.208 \\
\hline $\mathrm{Pb}$ & & & & & & & 1.000 & 0.246 \\
\hline $\mathrm{Zn}$ & & & & & & & & 1.000 \\
\hline
\end{tabular}

In the blood of periodontal patients, the highest concentrations of following essential elements, Fe (451.3 $\left.\mathrm{mg} \mathrm{L}^{-1}\right), \mathrm{Ca}$ (87.0 $\left.\mathrm{mg} \mathrm{L}^{-1}\right), \mathrm{Mg}\left(37.1 \mathrm{mg} \mathrm{L}^{-1}\right), \mathrm{Zn}\left(2.2 \mathrm{mg} \mathrm{L}^{-1}\right)$ and $\mathrm{Cu}$ (0.6 $\left.\mathrm{mg} \mathrm{L}^{-1}\right)$, were observed (mean values; Table 2$)$. The other metals were present in trace amounts.

The measured concentrations were compared to the results for healthy people reported in other studies [21, 22]. The levels of $\mathrm{Cd}, \mathrm{Cu}, \mathrm{Fe}, \mathrm{Mg}, \mathrm{Mn}$ and $\mathrm{Pb}$ in the blood were similar in the examined groups, while the patients were characterized by considerably higher concentrations of $\mathrm{Ca}$ and $\mathrm{Zn}$. This comparison is only to be used as an approximate reference and on statistical analysis can be applied to these data.

In the next step, the concentration of metals in the examined biological samples was compared in order to confirm whether oral fluid can be used as alternative material for the assessment of elemental status. Samples of blood and oral fluid were collected simultaneously from nine patients with periodontitis. The correlation coefficient of each pair of selected elements in these body fluids was calculated and it ranged from $r=-0.413(\mathrm{Zn})$ to $r=0.336(\mathrm{Ca})$. The results suggested that there were no strong linear correlations between the concentrations of metals $(p<0.05)$. The mean concentrations of all elements, with the exception of $\mathrm{Cd}$, were statistically significantly different from each other in the blood and the oral fluid (Mann-Whitney test, $p<0.05$ ).

\section{Correlation Study}

The metal-to-metal correlations in the oral fluid of periodontal patients and controls were investigated, and the results were presented in Tables 3 and 4. For patients affected by periodontitis, Ca was positively correlated with many metals: $\mathrm{Pb}$ $(r=0.752), \mathrm{Mg}(r=0.540)$, and $\mathrm{Cd}(r=0.455)$. Other notable correlations were $\mathrm{Fe}-\mathrm{Mn}(r=0.499)$ and $\mathrm{Pb}-\mathrm{Cd}(r=0.400)$. A quite similar pattern of mutual relationships between the elements was observed in the case of the control group. Strong positive correlations were again found between $\mathrm{Ca}$ and three metals: $\mathrm{Mg}(r=0.782), \mathrm{Pb}(r=0.652)$ and $\mathrm{Zn}$ $(r=0.540)$. Additionally, some significant correlations were also observed between $\mathrm{Mg}$ and two elements: $\mathrm{Pb}(r=0.456)$ and $\mathrm{Zn}(r=0.384)$.

Accordingly, principal component analysis was employed to visualize the interactions between selected metals in the oral fluid of the two groups. Figure 1 shows the score plots for the first two PCs (PC1-PC2) and was constructed from variables (the concentrations of elements in the oral fluid). The direction of vector indicates its correlations with another vector. The smaller angle between two vectors represents stronger correlations between the variables. In the group of periodontal patients (Fig. 1a), significant positive associations can be observed between $\mathrm{Zn}-\mathrm{Fe}, \mathrm{Fe}-\mathrm{Pb}$,
Table 4 Correlation coefficient matrix of selected elements in the oral fluid of healthy donors $(n=29)$

\begin{tabular}{|c|c|c|c|c|c|c|c|c|}
\hline & $\mathrm{Ca}$ & $\mathrm{Cd}$ & $\mathrm{Cu}$ & $\mathrm{Fe}$ & $\mathrm{Mg}$ & $\mathrm{Mn}$ & $\mathrm{Pb}$ & $\mathrm{Zn}$ \\
\hline $\mathrm{Ca}$ & 1.000 & -0.349 & 0.335 & 0.028 & $0.782 *$ & -0.224 & $0.652 *$ & $0.540^{*}$ \\
\hline $\mathrm{Cd}$ & & 1.000 & 0.016 & 0.124 & -0.263 & -0.065 & -0.236 & 0.026 \\
\hline $\mathrm{Cu}$ & & & 1.000 & 0.353 & 0.289 & 0.177 & 0.113 & 0.325 \\
\hline $\mathrm{Fe}$ & & & & 1.000 & -0.054 & 0.350 & -0.123 & -0.004 \\
\hline $\mathrm{Mg}$ & & & & & 1.000 & -0.130 & $0.456^{*}$ & $0.384 *$ \\
\hline $\mathrm{Mn}$ & & & & & & 1.000 & -0.066 & -0.207 \\
\hline $\mathrm{Pb}$ & & & & & & & 1.000 & 0.320 \\
\hline $\mathrm{Zn}$ & & & & & & & & 1.000 \\
\hline
\end{tabular}


a

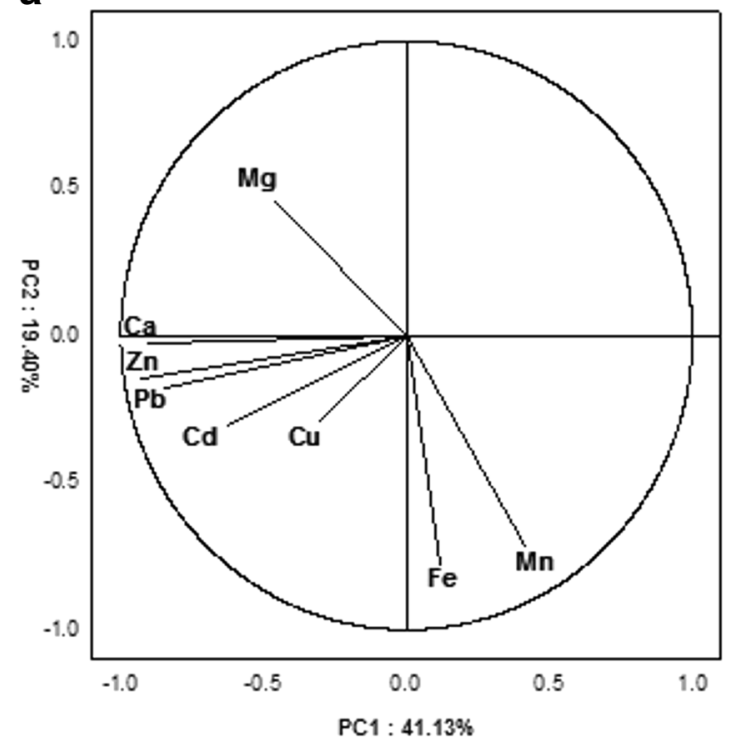

b

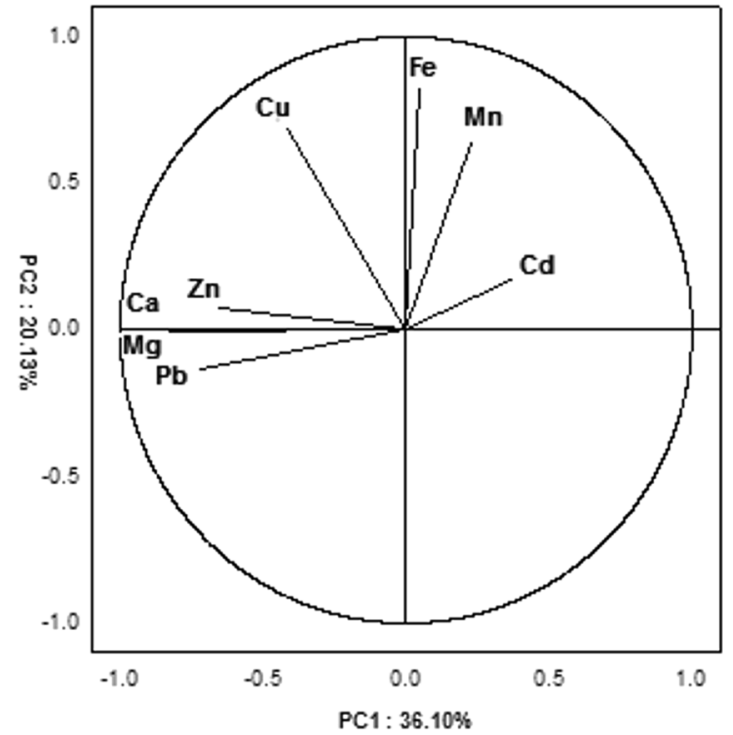

Fig. 1 Projection of variables: the concentration of metals in the saliva of patients with periodontitis (a) and healthy volunteers (b), on the plane of two first principal components (PC1 and PC2)

$\mathrm{Co}-\mathrm{Ca}, \mathrm{Co}-\mathrm{Zn}$ and $\mathrm{Pb}-\mathrm{Cr}$. Concentration of $\mathrm{Cd}, \mathrm{Mn}$ and $\mathrm{Mg}$ in oral fluid was inversely associated with the rest of the elements. In the case of control group (Fig. 1b), strong positive correlations were found between the following elements, $\mathrm{Ca}-$ $\mathrm{Mg}, \mathrm{Zn}-\mathrm{Co}, \mathrm{Ca}-\mathrm{Co}, \mathrm{Ca}-\mathrm{Zn}$ and $\mathrm{Pb}-\mathrm{Mg}$, while $\mathrm{Cr}$ were negatively correlated with the majority of metals. A visual examination of Fig. 1 showed that the pattern of mutual dependence of metals in oral fluid of patients was different from those of healthy donors.

\section{Cluster Analysis}

To examine whether it is possible to diagnose periodontal diseases on the basis of elemental content in oral fluid, hierarchical cluster analysis was performed. The results obtained are presented in the form of a clustering diagram in Fig. 2. It can be seen that the examined samples were divided into two groups at a linkage distance of 120 . The top cluster contained periodontal patients (with three exceptions), while the second cluster had mostly healthy donors (with four exceptions). Considering the number of samples (40), it can be concluded that classification based on concentrations of eight metals in oral fluid gave satisfactory results.

\section{Discussion}

Traditional clinical methods of periodontal disease diagnosis include the evaluation of several parameters (e.g. $\mathrm{CAL}=$ clinical attachment level, $\mathrm{PD}=$ probing depth) and radiographic measurements. They have some limitations, so many scientists try to find valid biomarkers which allow not only early detection of periodontal diseases but also evaluation of treatment effects [25, 26]. Recent examples of biomarkers are microRNAs (miRNAs) [26] and interleukin-1 $\beta$ (IL-1 $\beta$ ) and prostaglandin E2 (PGE2) in saliva [27], or matrix metalloproteinase (MMP)-9 [28] and neutrophil gelatinase-associated lipocalin (LCN2) in gingival crevicular fluid [28].

Additionally, some studies have focused on a possible association between inorganic ions in oral fluid and periodontal disease. Khamees et al. [29] found that the levels of $\mathrm{Na}$ and $\mathrm{Ca}$ in patients with chronic periodontitis were significantly higher than in a control group, while no significant difference in the concentrations of $\mathrm{K}$ and $\mathrm{Mg}$ was found. Also there was a significant negative correlation between $\mathrm{Na}$ and the clinical attachment level (CAL) and a positive correlation between $\mathrm{Ca}$ and this periodontal parameter. In our study, there were no significant differences in the concentration of $\mathrm{Ca}$ between the periodontitis and control group but patients had a slightly elevated level of this metal. This agreed with results obtained by Sewón et al. [30] and Acharya et al. [31]. Authors concluded that the oral fluid concentration of $\mathrm{Ca}$ can be a risk factor for the development of periodontal diseases. Increased level of metal in saliva probably affects the mineralization of dental plaque and hence calculus formation [32]. Unremoved dental calculus can cause gingivitis that can further develop into periodontitis [19].

The results obtained in our laboratory for the concentration of $\mathrm{Mg}$ in oral fluid were in good agreement with the results reported by other authors [33, 34], who also found that patients with periodontitis had a higher oral fluid level of this metal than healthy people.

There have only been a few studies of the levels of elements other than main electrolytes (like $\mathrm{Ca}$ and $\mathrm{Mg}$ ) in oral fluid. Mahmood et al. [34] measured the concentration of 
Fig. 2 The dendrogram obtained for saliva representing cases from control group (CG1-CG20) and patients with periodontitis (P1-P20)

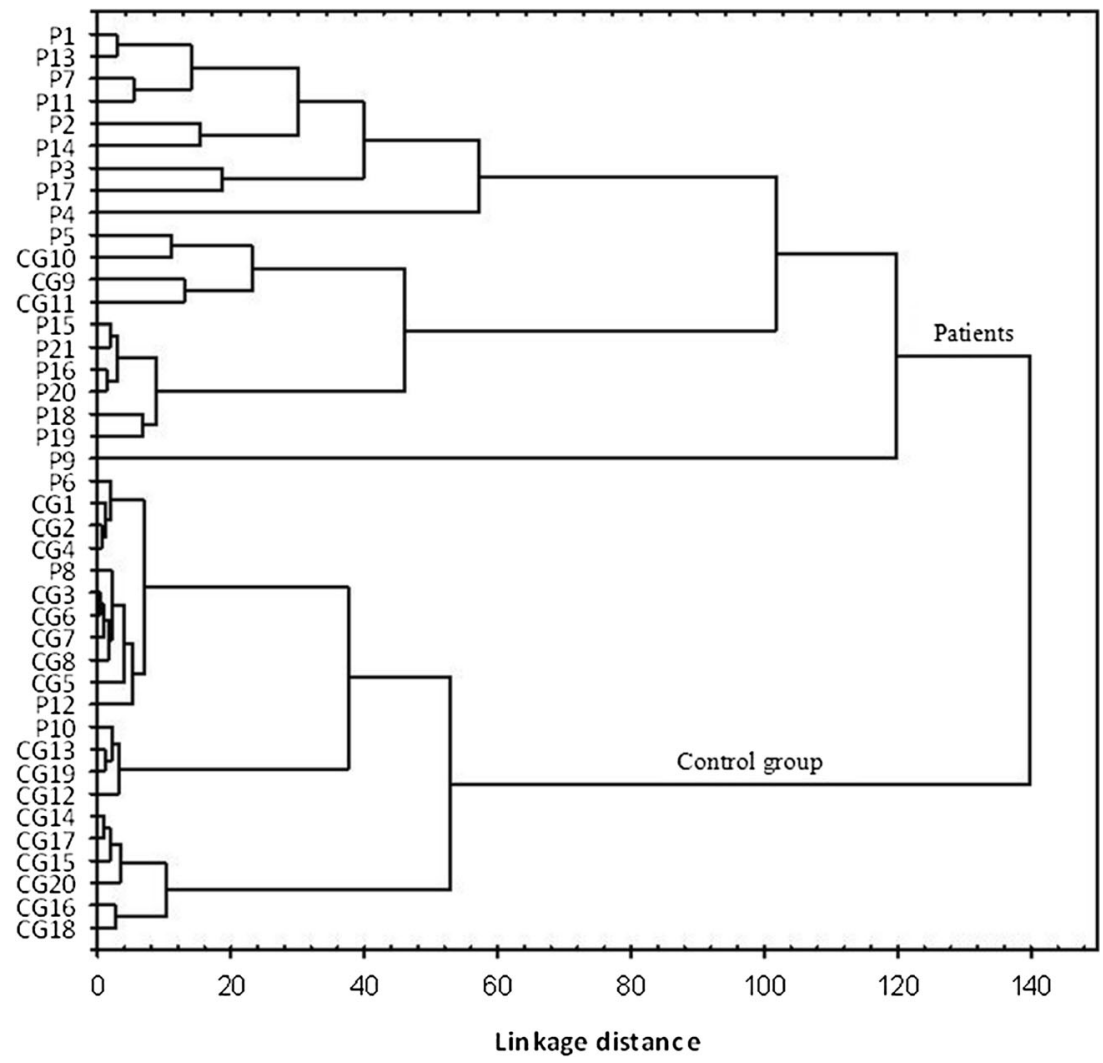

three oral fluid metals: $\mathrm{Zn}, \mathrm{Cu}$ and $\mathrm{Mg}$. They observed that the concentrations of $\mathrm{Cu}$ were significantly higher $(p<0.001)$, while $\mathrm{Mg}$ and $\mathrm{Zn}$ concentrations were lower $(p<0.001)$ in the group of patients than in controls. In our study, the periodontal group also had an increased concentration of all these metals in oral fluid $(p<0.05)$, but the differences were statistically significant for $\mathrm{Cu}$ and $\mathrm{Mg}$.

Cluster analysis, due to a significantly different distribution of the eight elements in the oral fluid of those examined, enabled the correct division of the samples into two groups: patients and healthy subjects. Such a statistical approach has successfully been applied in distinguishing between drug-free people and drug abusers [35], the diagnosis of cancer [24] and Parkinson's disease [36]. To our knowledge, there have been no reports of the classification of periodontal patients by cluster analysis based on metal concentrations in saliva.

The relationship between concentrations of metals (both in oral fluid and blood), and periodontal disease, as also the possibility of diagnosis on that basis, may in the future serve to prevent the development of such diseases, as well as to treat existing ones.

\section{Conclusion}

The present study was aimed at exploring the changes in the content of metals in the oral fluid and blood of patients affected by periodontal disease. The paper also examined the use of cluster analysis in the classification of samples of saliva based on the concentration of selected metals.

Salivary metal levels varied over a relatively wide range. Most of the examined elements were detected at elevated concentrations in the saliva of periodontal patients. However, the differences were statistically significant $(p<0.05)$ in the case of three metals: $\mathrm{Cu}, \mathrm{Mg}$ and $\mathrm{Mn}$.

The correlation study revealed that there were noticeably different mutual dependences of the selected elements in the saliva of two groups: patients affected by periodontitis and the healthy controls. There were fewer correlations between metals in the saliva of patients than in the controls.

The results of cluster analysis indicate that the metal profiles of oral fluid in those with periodontal disease are different from the controls. The data obtained from this study can be a basis for the future development of diagnostic and prognostic biomarkers for periodontal disease.

Acknowledgments The studies were financially supported by National Science Centre, Krakow, Poland (NCN, Grant No. N N404 202 139).

\section{Compliance with Ethical Standards}

Conflict of Interest The authors declare that there are no conflicts of interests. 
Open Access This article is distributed under the terms of the Creative Commons Attribution 4.0 International License (http:// creativecommons.org/licenses/by/4.0/), which permits unrestricted use, distribution, and reproduction in any medium, provided you give appropriate credit to the original author(s) and the source, provide a link to the Creative Commons license, and indicate if changes were made.

\section{References}

1. Herman M, Przybyłowicz A, Florek E, Piekoszewski W (2013) Method of determination of low copper concentration in human hair and nails. J Anal Chem 68:1-8

2. Koka S, Wong DT (2008) Perceptions of saliva: relevance to clinical diagnostics. In: Wong DT (ed) Saliva diagnostics. Wiley-Blackwell, New Delhi, pp. 104-111

3. Ivanenko NB, Ganeev AA, Solovyev ND, Moskvin LN (2011) Determination of trace elements in biological fluids. J Anal Chem 66:784-799

4. Bolann BJ, Rahil-Khazen R, Henriksen H, Isrenn R, Ulvik RJ (2007) Evaluation of methods for trace-element determination with emphasis on their usability in the clinical routine laboratory. Scand J Clin Lab Invest 67:353-366

5. Fang C, Wang X, Wu W, Gu X, Ye T, Deng H, Wang X, Shen F (2015) Association of serum magnesium level with odds of prediabetes and diabetes in a southern Chinese population: a prospective nested case-control study. Biol Trace Elem Res. doi:10.1007/ s12011-015-0594-y

6. Bornhorst JA, McMillin GA (2006) Trace and toxic elemental testing in the clinical laboratory. Lab Med 37:690-696

7. Zhang L, Zhu Y, Hao R, Shao M, Luo Y (2015) Cadmium levels in tissue and plasma as a risk factor for prostate carcinoma: a metaanalysis. Biol Trace Elem Res. doi:10.1007/s12011-015-0576-0

8. Tan C, Chen H (2011) Screening of prostate cancer by analyzing trace elements in hair and chemometrics. Biol Trace Elem Res 144:97-108

9. Tan C, Chen H, Xia C (2009) The prediction of cardiovascular disease based on trace element contents in hair and a classifier of boosting decision stumps. Biol Trace Elem Res 129:9-19

10. Saghir M, Shaheen N, Shah MH (2011) Comparative evaluation of trace metals in the blood of hepatitis $\mathrm{C}$ patients and healthy donors. Biol Trace Elem Res 143:751-763

11. Zhang Z, Zhuo H, Liu S, Harrington PB (2001) Classification of cancer patients based on elemental contents of serum using bidirectional associative memory networks. Anal Chim Acta 436:281-291

12. Tan C, Chen H, Zhu W (2010) Classification models for detection of lung cancer based on nine element distribution of urine samples. Biol Trace Elem Res 142:18-28

13. Wozniak A, Napierala M, Golasik M, Herman M, Walas S, Piekoszewski W, Szyfter W, Szyfter K, Golusinski W, Baralkiewicz D, Florek E (2016) Metal concentrations in hair of patients with various head and neck cancers as a diagnostic aid. Biometals 29:81-93

14. Pihlstrom BL, Michalowicz BS, Johnson NW (2005) Periodontal diseases. Lancet 366:1809-1820

15. Haake SC (2002) Etiology of periodontal diseases. In: Newman MG, Takei HH, Carranza FA (eds) Carranza's clinical periodontology, 9th edn. WB Saunders Company, Philadelphia, pp. 95-252

16. Bachanek T, Chalas R, Tarczydlo B, Pawlowicz A (2003) Evaluation of Millers' dental health. Part II. State of the parodontium. Ann Agric Environ Me 10:257-259

17. Jaedicke KM, Preshaw PM, Taylor JJ (2016) Salivary cytokines as biomarkers of periodontal diseases. Periodontol 70:164-183
18. Korte DL, Kinney J (2016) Personalized medicine: an update of salivary biomarkers for periodontal diseases. Periodontol 70:26-37

19. Salminen A, Gursoy UK, Paju S, Hyvärinen K, Mäntylä P, Buhlin K, Pussinen PJ (2014) Salivary biomarkers of bacterial burden, inflammatory response, and tissue destruction in periodontitis. $\mathrm{J}$ Clin Periodontol 41:442-450

20. Przybyłowicz A, Chęsy P, Herman M, Parczewski A, Walas S, Piekoszewski W (2012) Examination of distribution of trace elements in hair, fingernails and toenails as alternative biological materials. Application of chemometric methods. Cent Eur J Chem 10:1590-1599

21. Nunes JA, Batista BL, Rodrigues JL, Caldas NM, Neto JA, Barbosa F Jr (2010) A simple method based on ICP-MS for estimation of background levels of arsenic, cadmium, copper, manganese, nickel, lead, and selenium in blood of the Brazilian population. J Toxic Environ Health A 73:878-887

22. Prohaska C, Pomazal K, Steffan I (2000) Determination of Ca, Mg, $\mathrm{Fe}, \mathrm{Cu}$, and $\mathrm{Zn}$ in blood fractions and whole blood of humans by ICP OES. J Anal Chem 367:479-484

23. Kim YJ, Kim YK, Kho HS (2010) Effects of smoking on trace metal levels in saliva. Oral Dis 16:823-830

24. Al-Rawi NH, Talabani NG (2005) Quantitative analysis of trace elements in saliva of oral cancer patients from Iraq. J College Dentistry 17:32-35

25. Stathopoulou PG, Buduneli N, Kinane DF (2015) Systemic biomarkers for periodontitis. Curr Oral Health Rep 2:218-226

26. Ji S, Choi Y (2015) Point-of-care diagnosis of periodontitis using saliva: technically feasible but still a challenge. Front Cell Infect Microbiol 5:65

27. Kim SH, Lee SY, Lee YM, Lee YK (2015) MicroRNAs as biomarkers for dental diseases. Singap Dent J 36:18-22

28. Sánchez GA, Miozza VA, Delgado A, Busch L (2013) Salivary IL$1 \beta$ and PGE2 as biomarkers of periodontal status, before and after periodontal treatment. J Clin Periodontol 40:1112-1117

29. Khamees SI, Mohammad AN, Majid AY (2012) Evaluation of inorganic ions and enzymes levels in saliva of patients with chronic periodontitis and healthy subjects. J Bagh College Dentistry 24: 93-97

30. Sewón LA, Karjalainen SM, Söderling E, Lapinleimu H, Simell O (1998) Association between salivary calcium and oral health. J Clin Periodontol 25:915-919

31. Acharya A, Kharadi MD, Dhavale R, Deshmukh VL, Sontakke AN (2011) High salivary calcium level associated with periodontal disease in Indian subjects-a pilot study. Oral Health Prev Dent 9:195200

32. Ali BG, Ali OH (2012) Detection of salivary flow rate and minerals in smokers and non-smokers with chronic periodontitis (clinical and biochemical study). J Bagh College Dentistry 24:68-71

33. Manea A, Nechifor M (2013) Research on plasma and saliva levels of some bivalent cations in patients with chronic periodontitis (salivary cations in chronic periodontitis). Rev Med Chir Soc Med Nat 118:439-449

34. Mahmood A, Shukri M (2012) Assessment of salivary elements (zinc, copper and magnesium) among groups of patients with rheumatoid arthritis and chronic periodontitis and its correlation to periodontal health status. J Bagh College Dentistry 24:87-92

35. Bermejo-Barrera $\mathrm{P}$, Moreda-Piñeiro A, Bermejo-Barrera A, Bermejo-Barrera AM (2002) Application of multivariate methods to scalp hair metal data to distinguish between drug-free subjects and drug abusers. Anal Chim Acta 455:253-265

36. Chwiej J (2010) The use of cluster and discriminant analysis in the investigations of the role of trace metals in the pathogenesis of Parkinson's disease. J Trace Elem Med Biol 24:78-88 